\title{
Evaluating an English for Specific Purposes Course for Law Students
}

\author{
Ana Yeraldín Acosta Salazar \\ Universidad Nacional \\ Universidad de Costa Rica \\ Carolina Brenes Burgos \\ Centro Cultural Costarricense Norteamericano \\ Costa Rica \\ Jackeline Castro Murillo \\ Colegio Técnico Profesional Bolívar \\ Costa Rica
}

\begin{abstract}
This article describes a supervised practice which was focused on creating and teaching an English for Specific Purposes course for law students. This course was based on the needs, wants, and lacks of the population. These aspects were previously identified by interviewing professionals in the area and carrying out a diagnostic test and a questionnaire to know the main interests of the population in using English for occupational purposes. The methodology used to teach the classes was task-based instruction; the students had to perform tasks like participating in a job interview and communicating orally and in written form with potential clients. From the main results, it can be concluded that the course was successful in preparing the students to perform the target tasks.
\end{abstract}

Key words: tasks, English for Specific Purposes (ESP), course effectiveness, course evaluation

\begin{abstract}
Resumen
Este artículo presenta los resultados de la evaluación de la efectividad de un curso de inglés con fines específicos para estudiantes de derecho. Dicho curso fue diseñado según los deseos y necesidades de la población, previamente identificados por medio de encuestas a profesionales en el área, un examen de diagnóstico y un instrumento enfocado en averiguar los mayores intereses de la población al utilizar el inglés en su vida profesional. El curso constaba de tres unidades enfocadas en facilitarle a la población el uso del inglés en el ámbito laboral. La metodología utilizada para impartir las clases fue task-based instrucction (instrucción basada en tareas), en la cual los estudiantes tenían que realizar tareas distintas con los objetivos de participar en una entrevista de trabajo y comunicarse de manera oral y escrita con clientes potenciales. Entre los resultados principales se pudo concluir que el curso fue muy efectivo en preparar a los alumnos para realizar las tareas meta.
\end{abstract}

Palabras claves: tareas, inglés con fines específicos, efectividad de un curso, evaluación de un curso 
s part of the Master's
Program in Teaching English
as a Foreign Language, we designed and implemented a thirteenweek ESP course for law students. Based on the needs, lacks, and wants of our population, we developed classes that would help our students participate in job interviews and deal with clients in both written and spoken form. The following article intends to demonstrate how effective the English for Law Students course was in preparing the students to achieve the goal of each unit.

\section{Literature Review}

Having a focus on Task-Based Language Teaching (TBLT) allows students to participate in tasks that resemble real-life situations. However, the teaching-learning process is not complete if outcomes are not appropriately assessed. For this reason, and in order to have a deeper understanding of the factors that make a course effective, the following literature review includes information regarding TBLT, course evaluation, and different types of rubrics that can be used to evaluate ESP students' performance. These theoretical components prove to be important for the English for Law Students course as they provide appropriate insight to determine how to improve and measure its effectiveness.

\section{Task-Based Language Teaching}

TBLT is an approach establishing the use of tasks as the focal point behind planning and instruction. Based on the principles of Communicative Language Teaching, the activities used intend to involve real communication, are based on tasks that promote learning, and present significant language for the learner (Richards \& Rodgers, 2001, p. 223). Additionally, Skehan (as cited in Richards \& Rodgers, 2001) defines tasks as activities which focus on achieving a product that resembles a real-life situation that requires language (p. 224). In this sense, tasks are not merely class activities that students perform to learn structures, grammar points, or vocabulary. By carrying out a task, students will engage themselves in situations that they could encounter in their everyday life. For this reason, the tasks should not only be challenging but also a means of acquiring and applying a skill.

Since TBLT confronts students with tasks they will possibly face outside the class, traditional evaluation may not be enough to assess students' performance. As the focal point of tasks is to reflect real-life situations, the purpose of the assessment should also reflect them. Furthermore, Ellis (2003), when explaining language assessment paradigms, claims that communicative language testing is a form of task-based assessment as it involves performance, is authentic, and is scored through real-life outcomes ( $p$. 283). This type of assessment is closely related to English for Specific Purposes (ESP) which focuses on giving students specific skills necessary to carry out an activity related to a distinct professional task. On the same note, English for Occupational Purposes (EOP), a branch of ESP, revolves around preparing students to perform tasks focusing on skills related to work aspects (e.g. requesting a legal document from a client). Therefore, this research 
project is based on the idea of assessing students on how to carry out EOP communicative tasks that would help them accomplish the goals of each unit. Furthermore, in order to create an environment in which both students and instructors learn and improve during the course, evaluation cannot focus merely on tests or grades for students. Course evaluation proves to be necessary as it could provide course developers with feedback on important areas of improvement.

\section{Course Evaluation}

Stake and Sullivan (as cited in Shawer and Alkahtani, 2012) establish that program evaluation is "undertaken to help programs identify weaknesses and strengths so that they can improve performance, demonstrate they deliver what they promise and justify why they should continue" (p. 1336). Therefore, course evaluation is a tool that provides a general picture of what a course was or is like, reveals important information that could improve the course if taught in the future, and proves if it was successful in meeting its goals or not. This kind of evaluation would be valuable to suggest further recommendations about class dynamics, to improve the goals and content of the course in the future, and to provide feedback to instructors. Diamon and Sudweeks (1980) broaden the definition of course evaluation by giving two roles to the design and implementation of academic courses. The first role of evaluation deals with providing the necessary information for course designers in terms of the goals, content and structure of the program. The second role of evaluation focuses on identifying what is happening during the course, what works and what does not work. To illustrate, program evaluation starts even before the implementation of the course as its goals, content, and structure have to meet the students' needs. Once the learning process begins, the teacher is responsible for observing and evaluating the extent to which the students' needs are fulfilled. Additionally, by paying attention to what is effective or not during the implementation of the course, changes can be made to improve it.

Whether they are carried out at the end of the course or during its implementation, program evaluations should consider certain aspects to provide significant results. As Brown (2007) points out, the teacher, the students, and the program are the main factors that an effective course evaluation should take into account (p. 159). This proves to be essential because, even though learning is an internal process, it is not isolated from other learners or the learning environment. All participants can learn from each other and contribute to the others' improvement. The first aspect to take into account when evaluating a course is the instructor. Teachers are probably the main evaluators as they are constantly paying attention to the students' and their own performance, the flow of the course from class to class, and goal achievement. Christie (2012) summarizes the perspective of several authors and defines these interpersonal skills as communication, conflict resolution/negotiation, collaboration/ teamwork, and cross-cultural skills. First, communication refers to the ability to listen, respond, obtain feedback, and maintain an open evaluation 
process. Second, conflict resolution/negotiation implies a respectful attitude towards the views expressed by others. Third, teamwork/collaboration is related to interpersonal skills, focused negotiation, and a sense of group purpose. Finally, cross-cultural skills are the active awareness, understanding, and appreciation of the context at hand and the uniqueness of the group. Taking Christie's descriptions into account, a successful course evaluator should be prepared to identify strengths and weaknesses of the teaching-learning process and his/her own performance, assess the participants' perspectives of course accomplishments and effectiveness, and receive and incorporate recommendations with a professional attitude. Additionally, teachers should know that there will always be something to improve; for this reason, decisions should be made in terms of what is more appropriate for the students instead of the teacher's convenience or preferences. Lastly, dealing with differences could be difficult sometimes, but by contextualizing tasks and respecting students in terms of cultural background, learning styles, and personality, teachers can focus on common needs, lacks, and wants.

The second aspect to take into account when carrying out a course evaluation is the students. Brown (2007) and Chavez (2000) agree on the fact that students' subjectivity might affect the validity of course evaluation results. These authors draw attention to the fact that students are influenced by their own opinion about the teacher and the materials or even their peers' considerations. Here, results might be a way of taking revenge towards the teacher, an effort to show that the instructor was "nice", or evidence of the unwillingness to read instructions in instruments. However, neither of these two researchers mentions how to solve the problem of students' subjectivity. Some possible alternatives to compensate this subjectivity are to raise students' awareness of the goals and course purpose and what is expected from them, have instruments with clear and concise instructions (read them with students if possible), and talk to them about the importance of their objective participation. When talking about students' perceptions, Brown (2004) establishes that self-assessment allows students to develop intrinsic motivation as their desire to excel increases; additionally, autonomy is also developed since students monitor and pursue their goals without the presence of an external factor (p. 270). This means that, by asking students to assess themselves during different moments of a course, they would feel their own perceptions of their learning are important. Additionally, they would be able to reflect on their strengths and weaknesses, look for new strategies to improve, and set new goals in terms of their learning. Therefore, one would say that teachers should take into account the results of self-assessment to make the necessary modifications to meet students' needs and wants. However, as Moore (2005) establishes, this type of assessment might be inaccurate as students' self-reports are sometimes biased. He claims that teachers "should supplement their [students'] self-reports of class-related behaviors with objective data that are obtained independently" (p. 55). Although self-assessment can provide great insight about students' perspectives, having class observations, using 
rubrics, and having performance-based assessment would help expand on students' perceptions and focus on specific areas of improvement.

The third and last aspect to take into account when carrying out a course evaluation is the program. Diamon and Sudweeks (1980) designed a 79-question checklist to create a comprehensive approach to course evaluation. Although all of the items included in the checklist are significant to course evaluation, only the most relevant ones for the purpose of this research will be mentioned: course objectives, content of the course, instructional strategies, procedures and criteria for evaluating students' achievement, and course outcomes. When talking about course objectives in an ESP context, the main aspects to take into account are how feasible and realistic the objectives are in terms of the abilities of the target population and the time available, how objectives resemble the competences students will need in their professional or academic life and the relationship between goals and students' expectations. In terms of the content of the course, the aspects to be considered are the relationship between the content and the course objectives, the information given, and its sequencing. Instructional strategies refer to activities, assignments, materials, and instructional roles. The procedures and criteria for evaluating students' achievement draw attention to assessment procedures and instruments, the extent to which they are adequate to evaluate students' work and achievements, and the extent to which they appear to be fair and objective. Lastly, course outcomes deal with the number of students who successfully complete the course, the evidence that shows ob- jective achievement, and course effects on students' interests. Once again, this information highlights the fact that this type of evaluation should be considered even before starting the course in order to design one that truly satisfies students' needs. Additionally, once the course has started, ongoing evaluation would allow instructors to thoroughly analyze if the course is meeting students' needs, to determine the extent to which the objectives are being accomplished, and to identify areas of improvement. Thus, the use of rubrics to evaluate students' performance becomes essential.

\section{Rubrics}

Different authors have mentioned the importance of using rubrics to facilitate the teaching-learning process since they may help teachers to pay attention not only to the content they will teach but also to the outcome they expect from students. Furthermore, having rubrics allows instructors to think about all the input students need to be able to carry out tasks successfully. In addition, giving students the rubrics that will be used to evaluate their performance can encourage them to work on the aspects they need to improve the most (Arter \& Mc Tighe, 2001). In terms of our ESP course, having rubrics will allow the students to be familiar with the expected outcome at the end of each unit.

When teachers want to evaluate students' performance in a class, they should design rubrics that include the criteria that will be used to determine the extent to which the desired outcome is accomplished. To do so, teachers should decide whether to use holistic, analytic, 
general, or task-specific rubrics based on their advantages and disadvantages in terms of designing and grading. Brookhart (2013) mentions that holistic rubrics can be easier to design and score because they include a general description of the students' performance (p. 8). Therefore, it takes teachers less time to assess students. However, these rubrics are not appropriate for formative assessment since a "single overall score does not communicate information about what to improve" (p. 8). Analytic rubrics may take more time to design and to score; nevertheless, they give more specific information about students' strengths and weaknesses. As a result, teachers can provide appropriate feedback or extra practice on specific skills to help students improve their performance. To illustrate, Arther \& Mc Tighe (2001) recommend "the use of analytical trait rubrics for day-to-day classroom use, where ongoing assessment is integrated with instruction and where specific feedback is needed to guide improvement of teaching and learning" (p. 23). General rubrics encourage students to self evaluate because if learners have them at the beginning of a course, they can be aware of the aspects they should pay more attention to when performing a task. Also, teachers can reuse rubrics because they include descriptions of several aspects that apply to different tasks. In addition, task-specific rubrics include a description of explicit content and tasks which can make the scoring process easier.

Considerations for evaluating a course should start since it is designed because, at that moment, the instructors have already set the objectives and goals based on students' needs, lacks, and wants. Therefore, it is important to have a clear idea of what aspects are going to be evaluated in order to show course effectiveness. In the case of the present research study, those aspects are students' performance and perceptions. In addition, in an ESP course that focuses on TBLT, it would be necessary to use rubrics that clearly and fairly assess the extent to which the desired tasks are accomplished. For this purpose, the following research questions were stated:

General Question

- How effective was the English for Law Students course in meeting its goals?

Specific questions

- To what extent are the goals of each unit of the English for Law Students course achieved in terms of the students' performance in evaluations?

- To what extent are the goals of each unit of the English for Law Students course achieved in terms of the students' perceptions?

\section{Methodology}

\section{Participants}

The participants for the study were 13 students from the Law major at the University of Costa Rica. Their entry level of English ranged from beginner to advanced based on the diagnostic test administered prior to the beginning of the course. The diagnostic test also showed that these students lacked legal vocabulary, strategies to communicate competently with clients, and structures which would facilitate comprehension in oral and written legal communication. 


\section{Context}

The English for Law Students course consisted of three units that would help the students to successfully perform in a job interview and communicate with clients both in spoken and written form. The course was 13 weeks long, and it was team-taught by three student teachers. In each session, two student teachers played the role of assistants and the third one was the leading teacher.

\section{Instruments}

In order to prove course effectiveness, two types of questionnaires and three quizzes were designed. The first instrument, an anonymous Course Evaluation Questionnaire, consists of a Likert scale with 13 statements that aimed at measuring the students' overall perception of the course, a scale designed for the students to state their level of satisfaction with the course, and two questions which were intended to ask students for their perception regarding the opportunities to practice the main task of the unit and suggestions for improvement. As the focus of each unit was different from each other, there were three versions of this instrument.

The second instrument was a nonanonymous Self-Assessment Questionnaire which was created to allow the participants to evaluate their own performance. This questionnaire consisted of three parts which asked students about the tasks and strategies aimed at in each unit. Furthermore, the students had to grade themselves based on the perceptions of their abilities to carry out the main task of each unit.
The third method to evaluate course effectiveness was three task-based quizzes which assessed the students' performance in terms of the main goal of each of the units. The first two quizzes were oral interviews, and the third one was a written quiz. Rubrics for all three quizzes were developed in order to objectively assess the students.

\section{Procedures}

At the end of each unit, the students would take a quiz based on the goal of the corresponding unit. As the focus of Units 1 and 2 was speaking, the two student teachers who were assistants that day would guide and assess the students in the five-minute task designed for the quiz while the teacher would continue with the class. For unit number one, the assistants took the role of an interviewer while in the second quiz they took the role of a client. In the case of Unit 3 , as the focus was writing, 40 minutes of the class were taken to carry out the task. The following class, the students filled out both the Self-Assessment and the Course Evaluation questionnaires. After the administration of quizzes, students' performance was compared with their opinions about the accomplishments of objectives as indicated in the self-assessment. The answers of the Course Evaluation Questionnaire were used to confirm if the students perceived the class dynamics to help them to accomplish the tasks.

\section{Results and Discussion}

The English for Law Students course consisted of three units. During 
unit one, the learners studied strategies and vocabulary to answer questions in a job interview. In the second and third unit, the students practiced other strategies and legal terms in order to communicate with clients in oral and written form. In order to measure its effectiveness, two questionnaires and three quizzes were developed, distributed, and analyzed. The analysis that follows encompasses the results gathered from these questionnaires and quizzes.

Table 1 shows students' perspectives on course objectives and dynamics in the three units covered.

Regarding course objectives, most of the students agreed on the fact that classes had a clear purpose. This is supported by the numbers since the 13

Table 1

Students' perceptions regarding class dynamics

\begin{tabular}{|c|c|c|c|c|c|c|}
\hline & \multicolumn{2}{|c|}{ Unit 1} & \multicolumn{2}{|c|}{ Unit 2} & \multicolumn{2}{|c|}{ Unit 3} \\
\hline & $\mathbf{A}$ & $\mathbf{D}$ & $\mathbf{A}$ & $\mathbf{D}$ & $\mathbf{A}$ & $\mathbf{D}$ \\
\hline \multicolumn{7}{|l|}{ Course Objectives } \\
\hline 1. Each class had a clear purpose. & 13 & 0 & 13 & 0 & 13 & 0 \\
\hline $\begin{array}{l}\text { 2. Classes successfully prepared students to achie- } \\
\text { ve the goal at the end of the unit. }\end{array}$ & 13 & 0 & 12 & 1 & 13 & 0 \\
\hline \multicolumn{7}{|l|}{ Course Dynamics } \\
\hline 1. Classes evidenced previous planning. & 13 & 0 & 13 & 0 & 13 & 0 \\
\hline $\begin{array}{l}\text { 2. Materials were relevant for you as a future } \\
\text { lawyer. }\end{array}$ & 13 & 0 & 13 & 0 & 13 & 0 \\
\hline 3. Materials were appealing. & 12 & 1 & 13 & 0 & 13 & 0 \\
\hline 4. Instructions were clear. & 13 & 0 & 13 & 0 & 13 & 0 \\
\hline 5. Instructions were helpful. & 13 & 0 & 13 & 0 & 13 & 0 \\
\hline 6. Classes included content related to law. & 12 & 1 & 13 & 0 & 12 & 1 \\
\hline 7. Time was used effectively. & 11 & 2 & 11 & 2 & 12 & 1 \\
\hline 8. Tasks resembled real-life situations. & 12 & 1 & 12 & 1 & 12 & 1 \\
\hline
\end{tabular}

* A: Agree, D: Disagree, $n=13$

students agreed with this statement. Closely related, the majority of the participants agreed on the fact that classes had prepared them to achieve the goal of each unit. Nevertheless, in Unit 2 , just one of the students disagreed. This might be because the students had only one opportunity to talk to outsiders acting as clients which was the goal of the unit. In addition, only half of the learners attended that class; this might have made students believe that more opportunities like this should have been offered. In terms of course dynamics, once again, most of the participants gave positive responses to all of the items. In addition, law-related content, real-life situations, and effective use of time did not meet the expectations of one or two students. We 
can conclude that, in the case of unit one, this could have happened because the focus was job interviews and most of the language required for that task was about strategies, strengths, weakness and general areas of law; therefore, the activities might not have met the students' expectations. However, it is unclear why one student perceived Unit 3 not to be law-related as it was centered in dealing with legal terminology in order to communicate with clients. Yet, this perception does not fully explain why five students perceived time to be used ineffectively; however, a possible explanation to this might be that it was not possible to have tasks focused on all the areas of law that the students were interested in; they might have considered that some units needed more classes than others, or in the specific case of the third unit, which was focused on writing, they might have thought that the speaking activities were not very necessary since they did not reinforce their writing skills.

Table 2 presents the students' level of satisfaction with the course in each of the units.

\section{Table 2}

\section{Students' level of satisfaction with the course}

\begin{tabular}{ccccc}
\hline Grade assigned & $\mathbf{7}$ & $\mathbf{8}$ & $\mathbf{9}$ & $\mathbf{1 0}$ \\
\hline Unit 1 & 0 & 1 & 6 & 6 \\
Unit 2 & 1 & 2 & 2 & 8 \\
Unit 3 & 2 & 3 & 3 & 5
\end{tabular}

*The results shown in the table are based on a scale from 1 to 10.1 being the lowest level of satisfaction (not satisfied) and 10 being the highest (very satisfied).

Regarding course satisfaction, the numbers in table 2 show that most of the students felt pleased with each of the units. However, in Units 2 and 3, the level of satisfaction of some students decreased which means that they might not have received what they expected. A possible reason for this is that, due to time constraints and the nature of the units, it was impossible to include all the areas of law the students had asked for during the needs analysis. Thus, as the instructors of the course, we based the selection of the content on the students' immediate needs and lacks by focusing on different areas of law that would have helped them achieve the goals of the units. Furthermore, the fact that some of the students wanted the teachers to be experts in law in the ESP course also affected their expressed level of satisfaction. To cope with this situation, we tried to include more legal vocabulary in each class as the students suggested in the Course Evaluation Questionnaire.

The second instrument used to analyze students' perceptions on their performance was a Self-Assessment Questionnaire which consisted of three parts where the students stated how they perceived their performance was at the end of each unit.

Table 3 displays the aspects the students considered they had improved at the end of the first unit. 


\section{Table 3}

\section{Aspects students considered they had improved in Unit 1}

\section{After Unit 1, students considered they could...}

1. include relevant information to answer questions in a job interview.

2. use legal vocabulary to answer questions in a job interview.

3 . pronounce the legal vocabulary studied in class correctly.

4. use body language successfully in a job interview.

5 . interrupt an interviewer politely during a job interview.

6. take turns in a job interview.

During the needs analysis process, we carried out a job interview to grade the students' speaking skills. In this diagnostic test, all the participants showed they needed to improve their performance in job interviews as they had problems with register, did not include legal vocabulary, provided vague ideas, and did not use strategies such as turn-taking, interrupting politely or paraphrasing. Table 3 shows which of these abilities the students considered they had improved in Unit 1. Based on the results, most of the students considered that, now, they are able to use legal vocabulary as well as to include relevant information to answer questions in job interviews. One of the areas we were very interested in was the use of strategies to avoid communication breakdowns in job interviews.
The majority of the students were not only aware of the strategies but also thought they were able to use them successfully. In general terms, most of the students perceived an improvement in all the abilities presented in the table which might be a result of having several opportunities to practice job interviews during the classes.

Table 4 shows the aspects the students considered they had improved at the end of the second unit.

Units 2 and 3 aimed to help the students communicate with clients. When talking about Unit 2, Table 4 displays that most of the students perceived an improvement in their abilities. What stands out is that almost all of the students felt they could use the strategy of paraphrasing to explain legal terms to clients. This is significant since, by

\section{Table 4}

\section{Aspects students considered they had improved in Unit 2}

\begin{tabular}{lcc}
\hline \multicolumn{1}{c}{ After Unit 2, students considered they could... } & YES & NO \\
\hline 1. orally provide relevant information to a client based on the legal situation given. & 10 & 3 \\
2. use legal vocabulary successfully to communicate with a client. & 10 & 3 \\
3. interrupt a client politely. & 11 & 2 \\
4. pronounce the legal vocabulary studied in class correctly. & 9 & 4 \\
5. take turns when having a conversation with a client. & 10 & 3 \\
6. paraphrase to explain legal terms to clients. & 12 & 1 \\
\hline
\end{tabular}


using this strategy during class, they were constantly practicing legal vocabulary from different areas of law as they would use them in a real-life situation. In other words, paraphrasing turned out to be the strategy they needed the most to explain legal terms to clients. Additionally, the students claimed that they could now use other strategies such as turn-taking and interrupting politely to communicate with clients successfully. Regarding statement number 4, where the numbers are not as high as the others, it is relevant to mention that the students might have been self-conscious about pronouncing vocabulary since some of the words introduced in this unit were very challenging. Additionally, the load of vocabulary introduced and the fact that some of the students missed classes could have influenced both acquisition and pronunciation of the vocabulary introduced. Thus, it seems that the students needed more time of the class to practice the pronunciation of new terms explicitly.

Table 5 presents the aspects the students considered they had improved at the end of Unit 3.

For Unit 3, the numbers in Table 5 highlight that all the students believed they had improved most of the aspects covered in terms of writing e-mails. However, three students thought they could not define legal terms in written form. This may be because many students were absent or late when we

\section{Table 5}

\section{Aspects students considered they had improved in Unit 3}

\begin{tabular}{lcc}
\hline \multicolumn{1}{c}{ After Unit 3, students considered they could... } & YES & NO \\
\hline $\begin{array}{l}\text { 1. provide relevant written information to a client based on the legal situation } \\
\text { given. }\end{array}$ & 13 & 0 \\
2. include clear and complete information in emails. & 13 & 0 \\
3. write formal and respectful emails to clients. & 13 & 0 \\
4. write emails that include a subject, introduction, and a leave-taking. & 13 & 0 \\
5. successfully define legal terms in written form. & 10 & 3 \\
6. successfully paraphrase to explain legal terms to clients in written form. & 13 & 0 \\
7. summarize the case/legal process to follow in written form. & 13 & 0 \\
\hline
\end{tabular}

taught vocabulary about certain legal cases in Unit 3 (for example, getting residency and criminal complaints). Then, these students could not define those terms in written form because they were not familiar with them. In addition, there was some information about legal terms studied in Unit 3 that the students did not even know in Spanish because it is not taught in the law major. However, we consid- ered this information was important since, as the expert we consulted and the students of the course who were already working mentioned, lawyers are expected to know this information once they start working. Additionally, the fact that some students were more advanced than others in the major would possibly explain why some were familiar with the terms and were able to explain those in written form. For 
instance, first-year students certainly do not know as many legal terms as fourth or fifth-year students. Consequently, the learners had to take extra time to be familiar with these legal terms and processes in Spanish to be able to define them in English.

Figure 1 displays the frequency with which the students did homework during the three units of the course.

The second part of the self-assessment instrument was intended to show how the students perceived their performance in the class. It was relevant to analyze the frequency with which the students did their homework since this would influence their performance during the class. Doing homework would facilitate performing the tasks because the students would be practicing how to do them outside the classroom as well. It is clear that, in all the units, the answers given are varied and no particular pattern stands out; nevertheless, a comparison between units 1 and 3 shows a decrease in frequency. As Figure 1 shows, in Unit 1, five students claimed to do the homework

Figure 1

\section{Frequency with which students} did homework

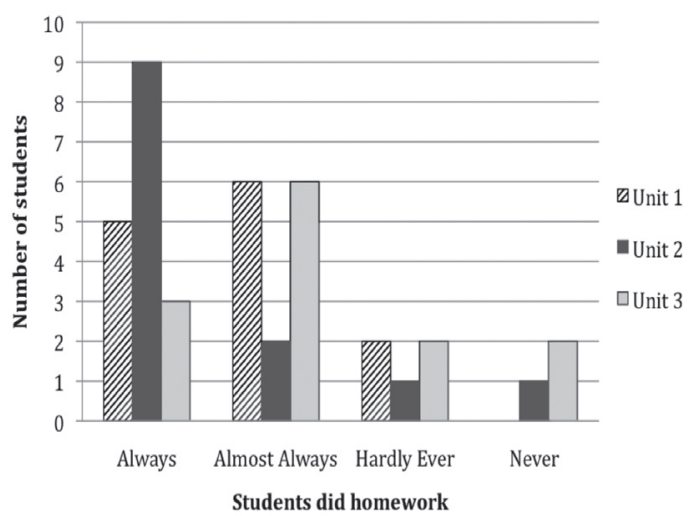

all the time. Contrastingly, in Unit 3, which required the students to write e-mails, some of the students ended up not doing their homework since it might have required more time and out-of-class work. It is relevant to point out that despite the fact that nine students gave positive answers for Unit 3, only five of them actually turned in the homework. This difference in numbers could be because some participants may have answered the questionnaire expecting to portray themselves as great students. As far as the phenomenon presented in Unit 2, where the students frequency did not present any significant change, it can be said that during Unit 2 most of the homework assigned was to study the legal terminology covered in class; thus, it was simpler. However, during Unit 3, the homework was more challenging because students had to go home and correct the e-mails which would take them more time.

Figure 2 presents the frequency with which the students came to class on time.

Figure 2

Frequency in regard to coming to class on time

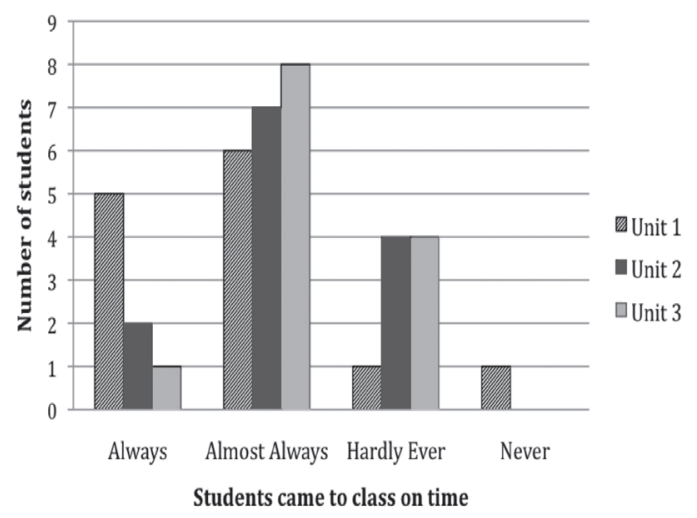


As far as coming to class on time, Figure 2 displays that, in Unit 1, eleven students stated that they came to class on time; in contrast, for Units 2 and 3, only nine people did. Attendance and punctuality were an issue since the beginning of the course because several students had classes that clashed with the course schedule. Consequently, an average of five students could not come on time to every class; this could have caused some of the negative responses. One can only speculate that this variation was caused because of the students' work schedule since some of them were hired while taking the ESP course. Coming to class on time became indispensable to reaching the goal of each unit since during the pretasks the students obtain the input to perform the tasks. Therefore, if they were not on time, they could not receive the necessary preparation to perform the main tasks which ultimately reflected the goals of the units.

Figure 3 displays the perceptions of the students about their participation in class. As the units progressed, lack of knowledge from previous classes evidently affected the students' performance; thus, if they had not come to class, their ability to participate would have been significantly hampered. The positive answers which go from eleven in Unit 1 to eight in Unit 3 support these ideas. The slight increase in students' participation in Unit 2 may be due to the introduction of new lawrelated topics. During Unit 1, the students were dealing with job interviews which meant that the class did not only relate to law. Unit 2, however, began introducing the students to legal vocabulary in English which may have spiked their interest and pushed them

\section{Figure 3 \\ Frequency in regard to participating in class actively}

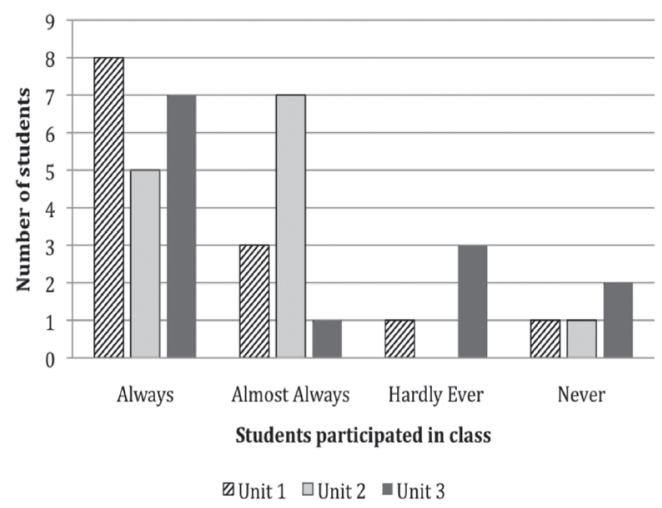

to participate more actively in class. Regarding the three students who stated they hardly ever participated in class, it can be said that including a topic which they had not covered as part of their major could have prevented them from participating because they did not feel they were experts in the field. Additionally, they might have felt tired due to the end of the semester. More to the point, it is relevant to mention that for some students writing is not an active skill; thus, they may have considered their participation lowered since the speaking activities also decreased.

Figure 4 shows the grades the students assigned to themselves at the end of each unit.

Figure 4 points out that all of the students considered that their performance in classes deemed them worthy of a passing grade. Additionally, as the course progressed, most of the students improved the grade they would give themselves. This might mean that, as they had to work harder because the unit load increased in terms of legal content and skills required, they might have believed they deserved a higher grade. 
Figure 4

Grade students assigned to their performance at the end of each unit

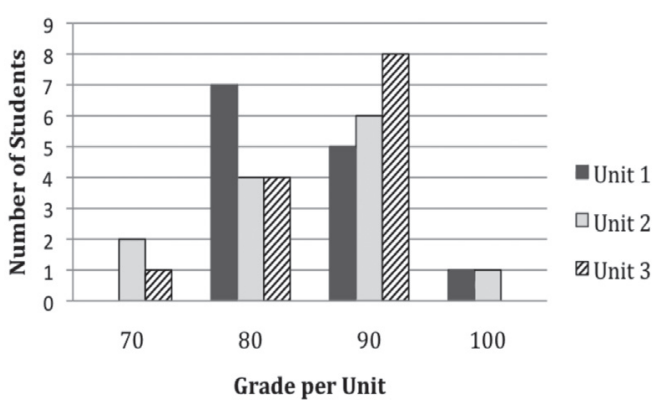

Table 5 shows the tasks the students perceived they could carry out at the end of Unit 1. It is relevant to highlight that, in all statements, a majority of positive answers were given. This fact allows us to say that the goal of Unit 1 was successfully accomplished according to the students' perceptions. Nevertheless, some of the answers show that the students still do not feel prepared to carry out some tasks. The students justified their responses stating that one of the main reasons was their lack of experience. Unit 1 focused on preparing the learners to effectively participate in a law-related job interview; consequently, they might have thought that having job experience was a requirement. If the students did not have experience in law, had not attended conferences, or had not worked it probably became difficult for them to communicate professional experience and past accomplishments with an interviewer despite their preparation to express themselves. Moreover, statements such as answering difficult questions and providing personal information became an issue for students because they said they were not used to answering questions about salary expectations or personal weaknesses. Certain types of questions they are likely to be asked during an interview are difficult to students not only because of the necessary grammatical structures but also because of the information they have to provide. In this case, even though the instructors did their best to prepare students to deal

Table 5

Students' perceptions regarding their task achievement in Unit 1

\begin{tabular}{lcccc}
\hline \multicolumn{1}{c}{ Now the students can.... } & $\begin{array}{c}\text { Strongly } \\
\text { agree }\end{array}$ & Agree & $\begin{array}{c}\text { Disagree } \\
\text { Strongly } \\
\text { disagree }\end{array}$ \\
\hline $\begin{array}{l}\text { 1. provide personal information during a job in- } \\
\text { terview. }\end{array}$ & 7 & 5 & 1 & 0 \\
$\begin{array}{l}\text { 2. talk about professional experience. } \\
\text { 3. talk about academic background. }\end{array}$ & 6 & 6 & 1 & 0 \\
4. talk about past accomplishments. & 7 & 5 & 0 & 0 \\
5. talk about future professional goals. & 8 & 5 & 1 & 0 \\
6. answer questions from an interviewer in a job & 6 & 6 & 1 & 0 \\
interview. & & & & 0 \\
7. answer difficult questions in a job interview. & 2 & 9 & 2 & 0 \\
8. behave professionally in a job interview. & 4 & 9 & 0 & 0 \\
\hline
\end{tabular}


with this type of questions, certain students still expressed uneasiness towards answering questions related to those topics. Lastly, as expressed by students, the sheer presence of fear caused them not to feel completely prepared to perform certain tasks. Some students commented they felt afraid of answering difficult questions because they were worried of providing poor answers.

Table 6 shows students' responses in relation to their perceived achievements of the expected tasks of Unit 2 in which the goal was to orally provide clients with legal services in terms of Costa Rican legislature.

Most of the answers provided are positive since most of the students felt they could, in some way, perform the tasks successfully. This demonstrates that, as far as students' perceptions go, the goal of Unit 2 was also successfully achieved since students considered themselves to be capable of performing the majority of the tasks. Nonetheless, one student disagreed with statements
1, 2, and 5. In regard to statement one, this might have been because there is no exact translation for certain legal terminology which in some cases caused confusion because some students expected certain false cognates to function as the translation for specific words. Concerning statements two and five, when asked about the reasons behind their responses, the students expressed that the ESP course was not to blame as they did not feel up to providing solutions or explaining legal processes because they lacked knowledge of the procedures to follow according to the law. Therefore, they could not perform the tasks not because they were not successfully prepared in terms of language use, but because they did not know the rules and regulations behind the legal topics studied.

Table 7 displays the students' perceptions regarding their task achievement at the end of Unit 3 in which the goal was to provide legal services to clients regarding Costa Rican legislature in written form.

Table 6

Students' perceptions regarding their task achievement in Unit 2

\begin{tabular}{lcccc}
\hline \multicolumn{1}{c}{ Now the students can... } & $\begin{array}{c}\text { Strongly } \\
\text { agree }\end{array}$ & Agree & Disagree & $\begin{array}{c}\text { Strongly } \\
\text { disagree }\end{array}$ \\
\hline $\begin{array}{l}\text { 1. orally explain legal terminology in } \\
\text { simple terms. }\end{array}$ & 6 & 6 & 1 & 0 \\
$\begin{array}{l}\text { 2. provide possible solutions to legal } \\
\text { problems. }\end{array}$ & 4 & 8 & 1 & 0 \\
$\begin{array}{l}\text { 3. deal with difficult clients. } \\
\begin{array}{l}\text { 4. ask clients for information and docu- } \\
\text { ments. }\end{array}\end{array} \quad 6$ & 7 & 0 & 0 \\
$\begin{array}{l}\text { 5. explain legal processes to clients. } \\
\text { 6. explain possible consequences of dif- } \\
\text { ferent legal actions. }\end{array}$ & 5 & 6 & 0 & 0 \\
\hline
\end{tabular}


Table 7

Students' perceptions regarding their task achievement in Unit 3

\begin{tabular}{lcccc}
\hline $\begin{array}{c}\text { Now the student can communicate with } \\
\text { clients through emails to... }\end{array}$ & $\begin{array}{c}\text { Strongly } \\
\text { agree }\end{array}$ & Agree & $\begin{array}{c}\text { Disagree } \\
\begin{array}{c}\text { Strongly } \\
\text { disagree }\end{array}\end{array}$ \\
\hline $\begin{array}{l}\text { 1. explain legal terminology from Costa Rican } \\
\text { legislature to clients in simple terms. }\end{array}$ & 5 & 7 & 0 & 0 \\
2. provide possible solutions to legal problems. & 4 & 8 & 0 & 0 \\
3. ask for information and documents. & 8 & 4 & 0 & 0 \\
$\begin{array}{l}\text { 4. explain possible consequences of different legal } \\
\text { actions. }\end{array}$ & 5 & 7 & 0 & 0 \\
\hline
\end{tabular}

The third unit of the course focused on helping students to build strategies to be able to communicate with clients in written form. Table 7 indicates that, at the end of this unit, all the students felt they could perform all the tasks regarding e-mail writing to a great extent. Some aspects such as having the possibility of practicing this skill several times could have helped them acquire most of the input they needed to perform those tasks in written form. More to the point, during the diagnostic test, results showed that the students required to learn how to write e-mails appropriately since their performance in this section of the test was very poor. Thus, one can infer that, due to the nature of the unit (developing writing skills), the participants might have had to work harder not only in class but also at home in order to improve their writing skills. Additionally, the large number of opportunities the students had to write e-mails in class helped them improve their writing skills significantly.

Not only the students' perceptions but also their performance on quizzes are important for the present research project. Consequently, the following section will be devoted to analyzing the results of the quizzes and comparing them with the students' perceptions.

Table 8 displays the last aspect to determine the effectiveness of the course which was the grades the students got in the quizzes they took at the end of each unit.

Although unit difficulty increased as they advanced, it becomes relevant to point out that the grades throughout the course remained relatively high. Taking Unit 1 as an example, which was about one of the aspects that required a lot of work based on the students' performance on the diagnostic test, the students' results significantly improved. Among the characteristics that the test showed needed improvement were register, legal vocabulary, and strategies. Accordingly, the quiz designed aimed at evaluating the students in those particular areas, among others. Thus, it can be easily concluded that, based on the grades gotten in the quiz, the course served to aid the students in improving their proficiency during job interviews. Despite the fact that students 1 and 3 had lower grades in the first quiz, overall performance was high. Lower grades might have resulted from the fact that it was the first evaluation the students had, 
Table 8

Students' grades on the quiz after each unit

\begin{tabular}{cccc}
\hline Student & $\begin{array}{c}\text { Quiz \#1: } \\
\text { Job Interview }\end{array}$ & $\begin{array}{c}\text { Quiz \#2: } \\
\text { Communicating } \\
\text { orally with clients }\end{array}$ & $\begin{array}{c}\text { Quiz \#3: } \\
\text { Writing to clients }\end{array}$ \\
\hline Student 1 & 72 & 80 & 93 \\
Student 2 & 84 & 84 & 87 \\
Student 3 & 76 & 88 & 90 \\
Student 4 & 84 & 88 & 93 \\
Student 5 & 84 & 84 & 83 \\
Student 6 & 96 & 96 & 100 \\
Student 7 & 84 & 80 & 83 \\
Student 8 & 92 & 100 & 97 \\
Student 9 & 80 & 76 & 93 \\
Student 10 & 84 & 84 & 90 \\
Student 11 & 88 & 96 & 87 \\
Student 12 & 88 & 96 & 90 \\
Student 13 & 95 & 96 & \\
\hline
\end{tabular}

so they were nervous about carrying out the job interview with one of the teachers and not with a classmate. Additionally, in most cases, the students did not know how to use the strategies appropriately, and they did not pronounce the -(e)d inflection which was necessary to talk about past academic accomplishments and work experience correctly.

Concerning Unit 2, not only did the numbers show improvement but also the students' performance in class significantly changed since they might have felt more confident among themselves and with the instructors. In addition, the topics of the course started to be more law-related which probably strengthened their motivation and thus facilitated students' performance. This is also supported by the fact that 12 out of 13 grades are above 80. Yet, student 9 still faced some dif- ficulties and his performance was poor. This could be due to the fact that during Unit 2, he had difficulty attending classes because of different personal reasons which might explain that his performance during the quiz was not up to par with the rest of the group even though assistants provided guidance and help during the classes in which he was present.

Regarding Unit 3, numbers show that all of the students' grades were above 83; this is significant since it indicates how effective the course was in preparing the students to successfully write e-mails to potential clients. Furthermore, it proves that all of the practice done in class and all of the strategies helped the students improve their writing skills. During the needs analysis process, the students underwent an examination which consisted of a diagnostic test where they had to 
write an e-mail to measure their entry proficiency level in writing. This test showed that the participants needed to include introductory sentences, greetings, and leave-takings, improve punctuation, use formal register, reduce wordiness, select appropriate wording, and include relevant content. When graded with the same scale used to grade the final quiz, the diagnostic test received grades that ranged from 27 to 87 while in Quiz 3 the grades ranged from 83 to 100. Thus, the progress is clear not only to the students since they felt they had notably improved but also to the instructors since the emails written by the end of the course were much more effective in informing a client about a legal case given.

Lastly, in relation to the comparison of the grades the students got in the quizzes, numbers show that the majority of the learners improved their performance in each of the units. To illustrate, three specific cases of students will be mentioned. Student 1 was ranked as a beginner in the diagnostic test; however, in the job interview (quiz \#1), this person was able to use most of the strategies studied in class and answer a majority of the questions correctly. In the second quiz, even though it was considered to be more complex due to the amount of legal vocabulary and the number of strategies that had to be implemented when communicating with a client, this student did a very good job. For the third quiz, the students had to work harder to improve their performance from the diagnostic test since they had a lot of weaknesses regarding writing e-mails. Furthermore, for this quiz, the learners had to know legal terms, phrases to explain legal processes and consequences, use appropriate greetings and leave-takings, include introductory and concluding sentences, and apply punctuation rules correctly. Nevertheless, student 1 was able to successfully write the e-mail including all the information requested and implementing most of the punctuation rules studied in class. The case of student 5 is worth mentioning as well. This student's performance did not vary a lot during the three quizzes $(84,84$, and 83 respectively). A possible explanation for this situation is that student 5 had problems with the schedule of the class, so she would usually arrive late and miss the pre-tasks that would help her improve in terms of legal vocabulary, practice strategies, and prepare to carry out the main task. As a result, she might not have improved as much as her classmates. Finally, student 9 got an 80 in the first quiz, but his grade lowered to a 76 in the second quiz. As aforementioned, due to some personal situations, he did not attend many of the classes corresponding to Unit 2. Since the goal of this unit was to orally communicate with clients, a lot of legal vocabulary was taught. Thus, during the quiz, he had problems with vocabulary and content which justifies his lower grade. However, for Unit 3, he attended every class on time and participated actively which led him to show significant improvement during the last quiz. To conclude, one would say that the improvement in the students' grades reflects the progress they made during the course.

Table 9 compares the overall grades the students obtained in each of the quizzes with the grades they assigned to themselves at the end of each unit. 
Table 9

Comparison of the students' overall performance on quizzes with their perception

\begin{tabular}{ccccccc}
\hline Grades & \multicolumn{2}{c}{ Unit 1 } & \multicolumn{2}{c}{ Unit 2 } & \multicolumn{2}{c}{ Unit 3 } \\
\hline & Quiz & Assigned & Quiz & Assigned & Quiz & Assigned \\
100 & 0 & 1 & 1 & 1 & 1 & 0 \\
90 & 3 & 5 & 4 & 6 & 8 & 8 \\
80 & 8 & 7 & 7 & 4 & 4 & 4 \\
70 & 2 & 0 & 1 & 2 & 0 & 1 \\
\hline
\end{tabular}

As shown in Table 9, in Unit 1 some of the students perceived their performance in the course to be worth of a high grade. Because they were aware of their high proficiency level in oral communication, they might have considered they deserved a high grade. Since Unit 1 focused on job interviews, they might have thought that the evaluation would be centered on their oral abilities and not necessarily on how well they carried out the task which included being able to include relevant information, deal with difficult questions, and use strategies. During the quiz, some of the students forgot the importance of including these aspects which make them get a lower grade than the one they expected. To illustrate, even though two of the students got a 70 on the quiz, none of them gave himself/herself this grade. In the case of Unit 2, numbers show that the students seemed to be more aware of the level of difficulty of the tasks they had to carry out because the comparison of the grades of the quizzes and the ones the students assigned to themselves did not vary a lot. During this unit, they had to learn a lot of legal vocabulary, implement strategies they had never used before, and find similarities and differences between Common and Roman Law to help clients un- derstand legal cases. When they took the quiz, they knew they had to successfully perform the task which was about explaining a legal situation to a client by providing solutions, asking for documents, and explaining possible legal consequences. Regarding Unit 3, the relationship between the students' perceptions and their performance is very precise. A possible reason for this is that they knew that writing was the skill they needed to improve the most. Furthermore, they were aware of the weaknesses they had when writing emails. Then, it was easier for them so see their improvement. It is important to point out that none of the students graded his/her performance with a 100 , which might show they still think they have to improve their writing skills.

At the beginning of the course, the students were very informal when participating in job interviews and when dealing with clients, lacked strategies that would facilitate communication and accuracy, and had several problems when writing emails. During the English for Law Students course, they learned structures and phrases that helped them to be more formal and address topics they did not feel comfortable with, such as talking about their weaknesses. Additionally, they learned how to deal with clients in a 
respectful and straight-forward way and how to use strategies as paraphrasing, turn-taking, self-monitoring, expressing empathy, use of proxemics, and checking comprehension. More to the point, class dynamics and games proved to be useful for the students' language acquisition. All these aspects demonstrate that the English for Law Students course was effective in meeting the goals.

\section{Conclusions}

After carrying out the needs analysis, designing and implementing the course, we arrived at two main conclusions. Firstly, since all the classes were prepared with the purpose of accomplishing the goals of their corresponding units, they had a clear ESP focus based on the needs, lacks, and wants identified during the needs analysis process. By using the Task-Based Approach, we were able to prepare the students to carry out tasks they would perform during job interviews and when dealing with clients. By having pre-tasks, we could introduce significant legal vocabulary, practice different strategies, and provide the input necessary to carry out the main tasks. Additionally, during the post-tasks, students received feedback on their main mistakes, practiced relevant structures, and explicitly studied the principles of mechanics. All this allowed us not only to identify the contexts where students needed English the most once they start working but also to understand their strengths and weaknesses as ESP students. Secondly, even when we had two instruments based on the students' perceptions (course evaluation and self-assessment), by using rubrics designed to evaluate the students' performance, we were able to obtain objective results which served to prove the effectiveness of the course on preparing the students to attain the goals. Based on the results obtained from all the instruments, i.e. course evaluation, self-assessment, and quizzes, we can conclude that the English for Law Students course was effective in meeting its goals to a great extent.

\section{Bibliography}

Arter, J. \& Mc Tighe, J. (2001). Scoring Rubrics in the Classroom: Using performance criteria for assessing and improving student performance. London: Corwin Press.

Brookhart, S. M. (2013). How to Create and Use Rubrics for Formative Assessment and Grading. Alexandria: ASCD Publications.

Brown, D. (2004). Language Assessment: Principles and Classroom Practices. New York: Pearson Education.

Brown, D. (2007). Teaching by Principles: An Interactive Approach to Language Pedagogy. New York: Pearson Education.

Chavez, M. (2000). Judgment Day: Students' Perspectives on End-ofCourse Evaluations. Die Uterrichspraxis / Teaching German, 33(2), 113-124. Retrieved from http:// www.jstor.org/stable/3531560

Christie, N. (2012). An Interpersonal Skills Learning Taxonomy for Program Evaluation Instructiors. Journal of Public Affairs Education, 18(4), 739-756. Retrieved 
from http://www.jstor.org/stable $/ 23272641$

Diamon, R. \& Sudweeks, R. (1980). A

Comprehensive Approach to Course Evaluation. Journal of Instructional Development, 4(1), 28-34. Retrieved from http://www.jstor.org/ stable/30220636

Ellis, R. (2003). Task-based Language Learning and Teaching. Oxford: Oxford University Press.

Moore, R. (2005). Advising Students in Developmental Education: How Accurate Are Developmental Education Students' Self-Assessments? Research and Teaching in Developmental Education, 22(1), 53-58. Retrieved from http://www.jstor.org/ stable/42802598
Nunan, D. (2004). Task-Based Language Teaching. Cambridge: Cambridge University Press.

Richards, J. C. \& Rodgers, T. S. (2001). Approaches and Methods in Language Teaching (Second ed.). Cambridge: Cambridge University Press.

Shawer, S. \& Alkahtani, S. (2012). The Relationship between Program Evaluation Experiences and Stakeholder Career Satisfaction. Creative Education, 3(8), 1336-1344. Retrieved from http://www.scirp. org/journal/PaperInformation. aspx? $\mathrm{Pa}$ perID $=25637 \# . \mathrm{VCuUyfl}-$ $5 \mathrm{NOA}$ 
